\title{
«We do not stop exercising because we grow old - we grow old because we stop exercising.» Dr Kenneth Cooper - Editorial 4/2019
}

\author{
EXERCISE IS MEDICINE
}

\section{Aerobics}

In 1968, Air Force Colonel Cooper wrote his first bestselling book, Aerobics, and sparked a fitness revolution. The general public got an idea of the multiple benefits of physical activity and exercise to improve or recover health and function. He developed his knowledge and training principles in the military, aiming to help soldiers stay fit and healthy. This led to the development of a fitness test most of us remember only too well: the 12-minute Cooper test. In 1970, retiring from the military, he founded the Cooper Aerobics Center in Dallas, which has hosted an Institute responsible for much of the research we have on the relationship between cardiorespiratory fitness and health outcomes, through the Aerobics Center Longitudinal Studies. These were pursued under the leadership of Pr Steven Blair [1] and became the largest ongoing observational study on fitness and health, with countless publications on more than 112 ’000 subjects.

\section{Exercise or Sports medicine}

Over the years, we as sports physicians have learnt a lot on physiology of extreme exercise and training for performance, and this has led us to develop clinical centres with multidisciplinary teams (medical specialties, physiotherapy, exercise physiology, sports nutrition, psychology and more). The sports medicine facilities aim to help athletes of all levels treat and recover from injuries and illnesses, or improve their training and performance. Gradually, as science progressed, we have become interested in best practices to reduce the burden of health conditions through preventative actions, and not just therapeutic action or on-field management.

However, this focus on sports and performance does not correspond to the majority of our daily clinical activity. We will regularly see non-elite athletes, or even rather inactive patients who come to us because we have expertise in musculoskeletal health management. The symptom may be knee or back pain, the treatment will inevitably involve some restoration of movement capacity. We call this training (or rehabilitation). Zooming away from the aching body part, we will often see a person with other medical issues that may benefit, as Dr Cooper envisioned 50 years ago, from our profession's experience and skillset. This is where our specialty's spectrum broadens beyond the sports focus, and where the inclusion of the concept of exercise brings new meaning and relevance in today's society. 


\section{Sport and Exercise Medicine Switzerland (SEMS)}

Four years ago, we introduced the new name of your journal, which integrated the "E" of Exercise. Following an international movement for the development of sports medicine, many countries have included the term "exercise" in their name (UK, Canada, Australia, France, Italy, Sweden, Belgium, to name a few). This will strengthen the relevance of sports medicine stakeholders within the wider spectrum of movement-related health conditions. At our Annual meeting in Interlaken this past October, the General Assembly voted to change our society's name (SGSM/SSMS) to a unified acronym including the "E" of exercise: Sport \& Exercise Medicine Switzerland/Schweiz/Suisse/Svizerra/Svizra (SEMS).

With every change come challenges, opportunities and responsibilities. First, as a society we must implement the change (logo, communication). Second, we must develop new partnerships/projects with various stakeholders, political/public, associative, academic and corporate, in order to strengthen our brand and promote our actions. As for the third element, each of us must ask himself/herself how he/she owns and promotes the addition of the "E" in everyday practice. We have a collective strength that can impact individuals and groups alike.

\section{The miracle cure?}

In this issue, we bring you three articles on exercise and the brain (role of exercise on dementia by Ngamsri et al, two articles on primary and secondary stroke prevention by Scutelnic et al) and one on a fascinating project for the grueling cycling Race Across America (RAAM) involving a sedentary person (Guex et al).

Recently, Dr Fiona Godlee, the editor in chief of the British Medical Journal (BMJ) wrote an editorial on "The miracle cure", empowering medical practitioners to embrace the science and the benefits of exercise for health with every opportunity: whether in counselling patients, or for themselves to stay active and be a role model in society. [2] We hope that you will appreciate the articles presented, and embrace her wise words, by staying active and promoting movement around you. Walking for 12 minutes can be good for health [3], and it does not have to be all out!

\section{Boris Gojanovic}

Editeur en chef editor@sgsm.ch

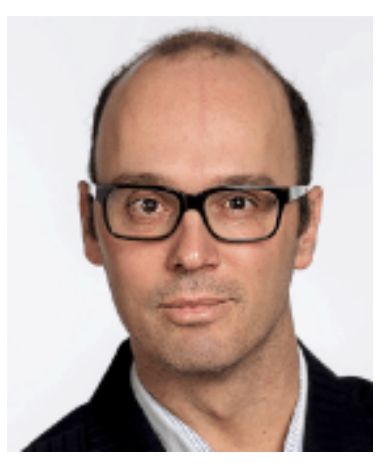




\section{References}

1. Blair SN, Kohl HW, 3rd, Paffenbarger RS, Jr., Clark DG, Cooper KH, Gibbons LW. Physical fitness and all-cause mortality. A prospective study of healthy men and women.

Jama.1989;262(17):2395-401.DOI:10.1001/jama.262.17.2395

2. Tine M. Acute aerobic exercise: an intervention for the selective visual attention and reading comprehension of low-income adolescents. Frontiers in psychology.

2014;5:575.DOI:10.3389/fpsyg.2014.00575

3. Godlee F. The miracle cure. BMJ. 2019;366:I5759.DOI:https://doi.org/10.1136/bmj.15759 